\title{
Experimental determination of the optimum percentage of asphalt mixtures reinforced with Nano-carbon black and polyester fiber industries
}

\author{
Babak Mirbaha $^{a^{*}}$, Ali Abdia ${ }^{a}$ Mohammad Zarei ${ }^{a}$, Ali Zarei ${ }^{\mathrm{b}}$ and Farzad Akbari nia ${ }^{\mathrm{a}}$
}

${ }^{a}$ Department of Civil Engineering, Imam Khomeini International University, Iran ${ }^{b} M S C$, Department of civil engineering, Razi University, Iran

\begin{tabular}{|c|c|}
\hline A R T I C L EI N F O & A B S T R A T T \\
\hline $\begin{array}{l}\text { Article history: } \\
\text { Received } 6 \text { April, } 2017 \\
\text { Accepted } 31 \text { August } 2017 \\
\text { Available online } \\
31 \text { August } 2017 \\
\text { Keywords: } \\
\text { Nano carbon-black } \\
\text { Asphalt concrete } \\
\text { Polyester fibers } \\
\text { Marshall stability } \\
\text { Cost analysis }\end{array}$ & $\begin{array}{l}\text { The cost of road construction or its repair is among the most concerns for the pavements } \\
\text { engineers. Cracking and degradation is common mode of failure in asphalt pavements that } \\
\text { occurs due to increasing traffic loads or even environmental conditions. For facing with these } \\
\text { damages, some solutions are proposed including correction, quality improvement and } \\
\text { increasing the asphalt resistance. In this research, by adding different percent amounts of black } \\
\text { nano-carbon and polyester fibers as modifier in the asphalt mixtures and conducting several } \\
\text { Marshall tests, it was observed that adding these two additives can improve generally the } \\
\text { Marshall results. Polyester fiber causes preventing crack and damages of asphalt because of } \\
\text { armed effect specification. According to the results, Marshall stability is increased up to } 61 \% \text {. } \\
\text { Furthermore, an economic analysis was performed to investigate the cost of using such } \\
\text { modified asphalt mixtures for constructing } 1 \mathrm{~km} \text { of a six line road and suitable percentages of } \\
\text { additives were found from mechanical-economic analyses. }\end{array}$ \\
\hline
\end{tabular}

(C) 2017 Growing Science Ltd. All rights reserved.

\section{Introduction}

Strengthening the asphalt mixtures by using the additives has been developed extensively in recent years. The pavement engineers have applied various additives to bitumen and asphalt mixtures to improve the mechanical and physical properties of asphalt mixtures. From the other hand, several failure modes, degradations and damages such as cracking, rutting and etc. can results in overall or partial failure of roads and pavements (Abuawad et al. 2015; Ameri et al., 2011, 2012; Abdelfattah et al., 2016; Sabouri et al., 2015; Chandak et al., 2017; Murugan et al., 2016; Park et al., 2015; Wang et al., 2017; Behbahani et al., 2013; Fazaeli et al., 2016). Annually huge amount of costs are spend for repair or reconstruction or rehabilitation of roads. For facing with these damages, some solutions are proposed including correction, quality improvement and increasing the asphalt resistance against

\footnotetext{
* Corresponding author.

E-mail addresses: mohammadzarei959@yahoo.com (M. Zarei) 
environmental or mechanical loads. Among the frequently used reinforcing additives, the fibers can prevent the damage of the asphalt surface because of their good reinforcing effects.

Zhao et al. (2014) performed a laboratory investigation on Bio-Char modified asphalt mixtures. They added black carbon as additive to the bitumen by the weight percentage of 5 and $10 \%$. Their results showed that the addition of black carbon has positive effect on the results of Marshal test. Khalid (2013) investigated the effect of physical and engineering properties of 60/70 bitumen modified with carbon black additive. Carbon black was added to the bitumen by approximately $4 \%$ of the bitumen's weight and it was observed that the softening point is increased for modified bitumen. Park \& Lovell (1996) reinforced the asphalt mixture of pavement by using pyrolyzed black carbon (PCB) obtained from wasted rubbers and observed that the higher percentage of PCB additive can result in more resistance of the mixture. Zahedi and Zarei (2016) investigated the effect of black Nano carbon on asphalt mixtures and concluded that black Nano carbon can change technical specifications of the asphalt and consequently improves the mechanical specification of the asphalt mixtures. Ameri et al. (2016) investigate the cracking response and fatigue life of asphalt mixtures modified with carbon nanotube additives. They showed that adding such modifier can influence significantly on the integrity and durability of asphalt mixtures. Shafabakhsh et al. (2014) investigated the influence of nano-TiO2 on the rutting and fatigue behavior of asphalt mixtures. The effect of different fibers on the tensile property of bitumen was studied by Abtahi et al. (2011). They used ordinary and texturized polyester fibers with the length of $12 \mathrm{~mm}$ in their study. However, they found that adding the polyester fibers can reduce slightly the tensile strength of bitumen. Shukla et al. (2014) performed an experimental study about the effect of polyester fibers and glass fibers of length $8 \mathrm{~mm}$ and $0.2 \mathrm{wt} \%$ of bitumen on strengthening the asphalt mixtures. Their results showed that Marshal Resistance is increased up to 13 percent by adding the fibers. Similarly in a laboratory work, Guan et al. (2014) studied some kinds of fibers for strengthening the mechanical properties of asphalt mixtures. They found that adding polyester fibers with high weight percentage can increases the Marshall Stability of mixture. Zarei and Zahedi (2016) investigated the simultaneous effect of polyester fiber and black Nano carbon in asphalt mixtures and observed improvement in the mechanical specifications of the asphalt mixtures. however; the weight, length and type of fiber had noticeable influence on the mechanical properties of the modified asphalt mixtures. In another research work Zahedi and Baharvand (2017) showed that adding nano-clay and crumb rubber can improve the strength properties of the hot mix asphalt concretes. However, in addition to the strengthening and reinforcing aspects a commercial additive should also be cost effective for using in practical pavement projects. Therefore, in this research, following a series of Marshal experiments conducted on mixtures with different additives, related economical and cost analyses are performed to obtain a better trade off benchmarks for using such modified asphalt concretes in practical paving projects.

\section{Materials and methods}

\subsection{Materials}

The required materials for manufacturing the asphalt mixturs of this research were bitumen, aggregates and polyester fibers as explained in the following.

In order to study the additives effect on mechanical properties of asphalt mixtures, asphalt samples were made by 80/100 base bitumen supplied from Kermanshah refinery (in the west of Iran). The aggregate gradation (as shown in Fig. 1) which is usually used for Topeka layer with sieve size of 0 to $19 \mathrm{~mm}$ was also used. As it was mentioned earlier, the size of Nano carbon black is classified into different types. Technical Properties of Black carbon used in this research is CAS NO.1333-86-4 type that its specifications have been presented in Table 1. In addition, polyester fibers (with chemical formula shown in Fig. 2) which has high stability were used for reinforcing the asphalt mixture. The fibers were supplied from tire Cord Company located in Kermanshah province (west of Iran). Some of the properties of the polyester fiber are listed in Table 2. 


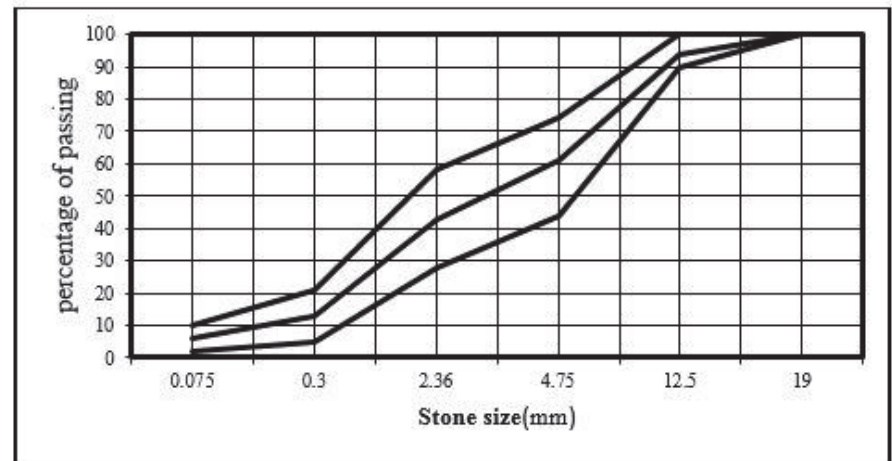

Fig. 1. Gradation of asphalt mixtures usually used for Topeka layers

Table 1. Specifications of used Nano carbon black

$\begin{array}{lcccc}\text { Classification } & \begin{array}{c}\text { Density bulk } \\ \left(\mathrm{g} / \mathrm{cm}^{3}\right)\end{array} & \begin{array}{c}\text { Surface area } \\ \left(\mathrm{m}^{2} / \mathrm{g}\right)\end{array} & \begin{array}{c}\text { Size }(\text { range }) \\ (\mathrm{nm})\end{array} & \text { (nm) Size used } \\ \end{array}$

Cas no. 1333-86-4

0.21

80

$15-300$ 42

Table 2. Specifications of polyester fibers used in this work

\begin{tabular}{ccccc}
$\begin{array}{c}\text { Melting } \\
\text { point } \\
\left({ }^{\circ} \mathrm{C}\right)\end{array}$ & $\begin{array}{c}\text { Tonicity or the breaking } \\
\text { stress } \\
(\mathrm{cN} / \text { tex })\end{array}$ & $\begin{array}{c}\text { Tonicity or the breaking } \\
\text { stress } \\
(\mathrm{gr} / \mathrm{denier})\end{array}$ & $\begin{array}{c}\text { Force in the breaking } \\
\text { point } \\
\text { b.s }\end{array}$ & $\begin{array}{c}\text { denier } \\
(\mathrm{gr})\end{array}$ \\
\hline $\mathbf{2 6 0 - 2 5 0}$ & 75 & 7 & 154 & 1980 \\
& & & & \\
\hline
\end{tabular}<smiles>COCCOC(=O)c1cccc(C(C)=O)c1</smiles>

Fig. 2. Chemical formulation of polyester fibers

For manufacturing the asphalt mixture first the aggregates and fibers were mixed and heated inside on oven then dried aggregates were mixed with nano carbon black modified bitumen at $150^{\circ} \mathrm{C}$. The mixtures were then prepared and compacted according to the standard method of ASTM-D1559 in the shape of Marshal test specimen and then tested. For investigating the effect of both polyester fiber and nano-carbon black additives, first, the extreme point of Marshall stability for different percentages of polyester fibers was obtained. Then the effect of nano-carbon black was studied on the results of Marshal test. Accordingly, the percent amounts of $0.1,0.2,0.3$, and $0.4 \%$ of polyester fibers with high stability and also 5, 10, 15 and $20 \%$ of black Nano carbon black were chosen for using in the mixture of asphalt samples.

\section{Results and discussion}

The experimental results obtained for the tested asphalt mixtures are described in this section.

\subsection{Analysis of Marshal Stability results}

Fig. 3a,b presents the results of Marshal stability for different modified asphalt mixtures. As seen from this figure, the combination of both additives (i.e. polyester and nano carbon) has caused to 
increase the Marshal stability, such that adding 15\% of Nano-carbon black and $0.4 \%$ of fibers has led to a stability equal to 1350 which indicates an increase up to $61 \%$ compared to the control sample. Also adding $15 \%$ of nano-carbon black and $0.3 \%$ of fibers has led to a stability equal to 1320 which indicates an increase of $58 \%$ stability compared to the base and un-modified sample. It seems that, when the fibrous materials are placed between aggregates, increase the locking and fastening of aggregates inside the asphalt concrete materials. The Nano-carbon black can increase the resistance of asphalt mixture due to the presence of carbon.

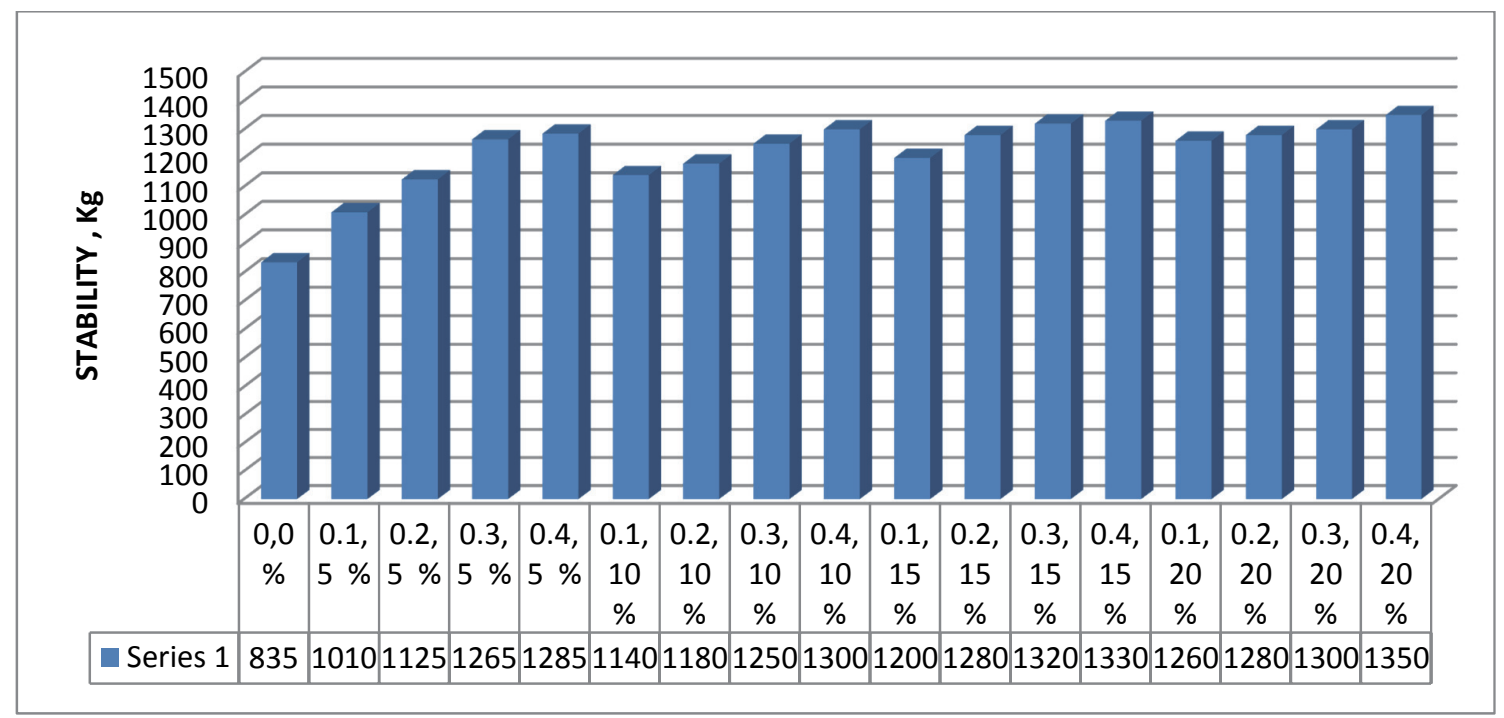

(a)

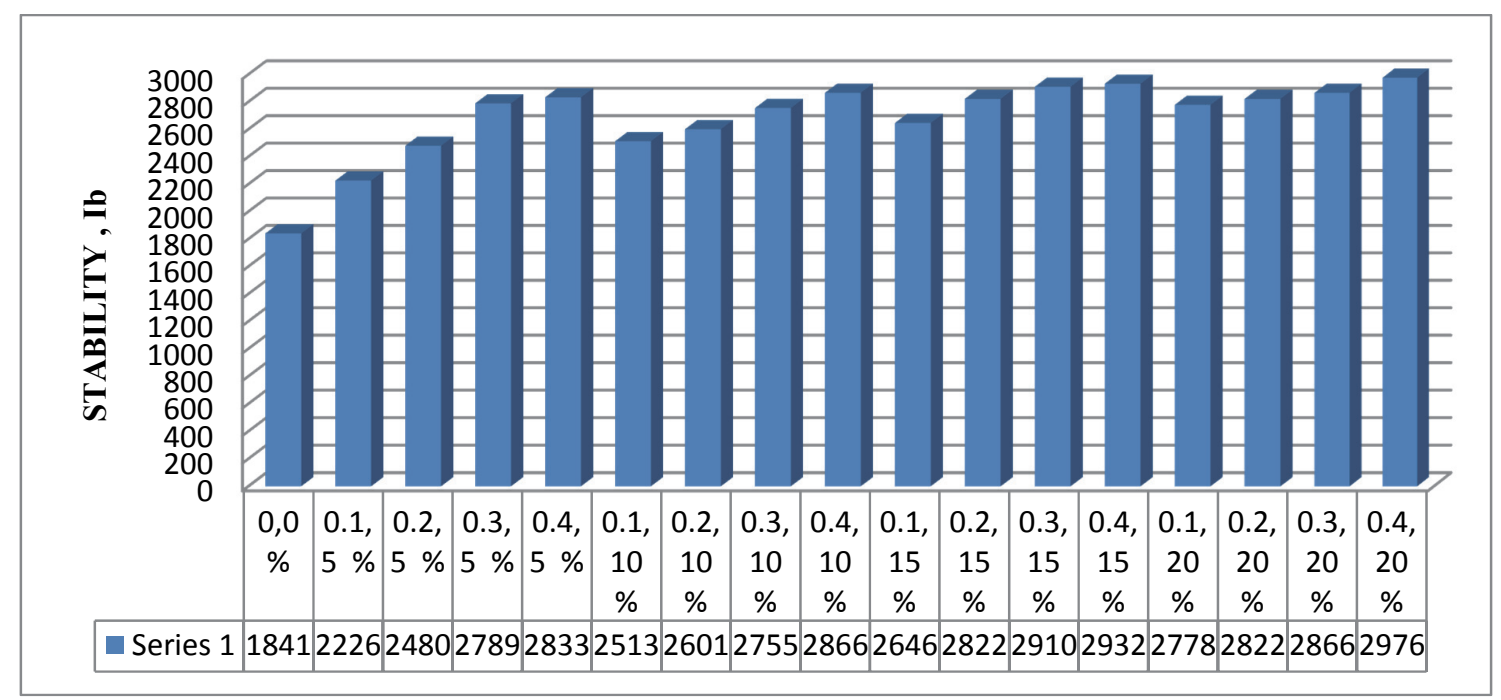

(b)

Fig. 3. The effect of adding nano-carbon black and polyester fibers on the Marshall Stability (a) in terms of $\mathrm{kg}$ and $(\mathrm{b})$ in terms of $\mathrm{lb}$ for the investigated asphalt mixtures

\subsection{The analysis of Marshal Flow results}

Fig. 4, shows the bar chart diagram of flow results for the tested asphalt mixtures. Based on this figure, by increasing nano-carbon black and polyester contents in the mixtures, the flow of mixture reduces due to some effects such as chemical reactions or the manner of absorption of nano-carbon black and polyester fibers with the base binder. 


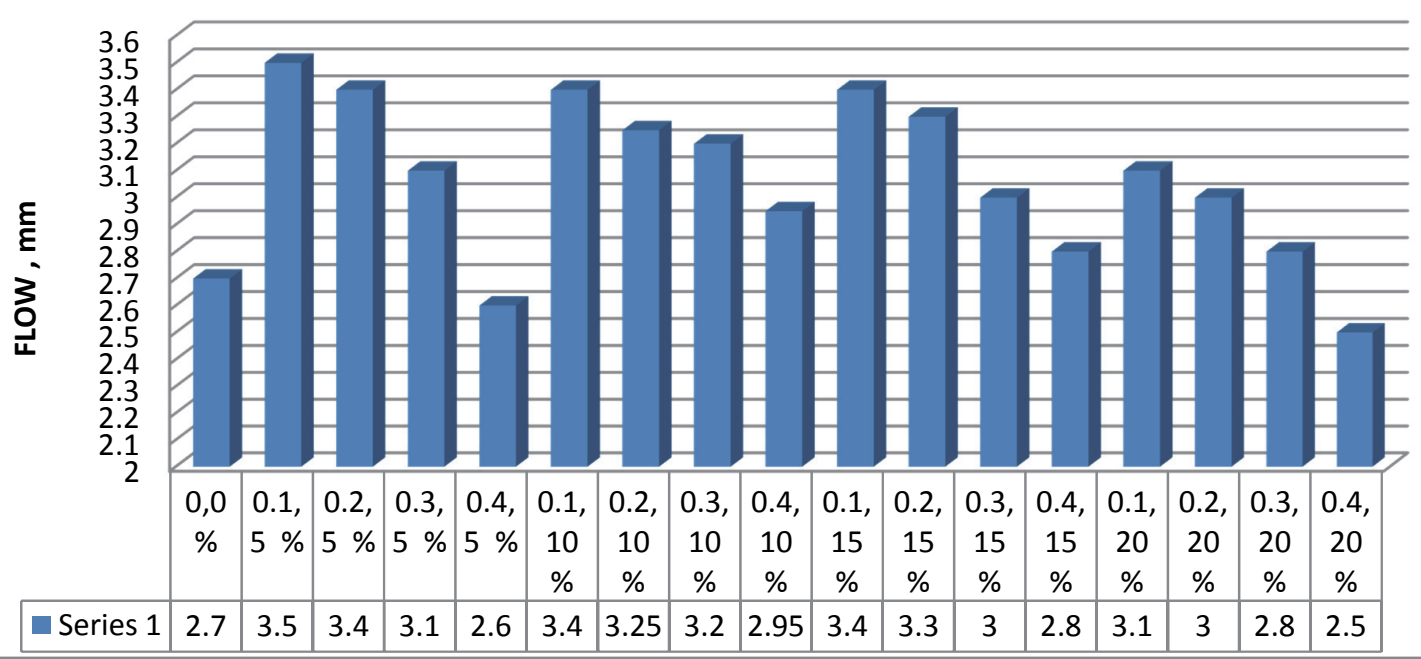

Fig. 4. The effect of adding nano-carbon black and polyester fibers on the flow of investigated asphalt mixtures during marshal test

\subsection{Analysis of unit weight results}

The variations of unit weight of mixture for different additives have been presented in Fig. 5. As it is observed from Fig. 5, by increasing the content of nano-carbon black up to $15 \%$ in the mixtures, the weight becomes greater by further adding this additive can reduce the unit weight of asphalt mixtures. Meanwhile, generally by increasing the fiber percentage the unit weight of mixture becomes smaller.

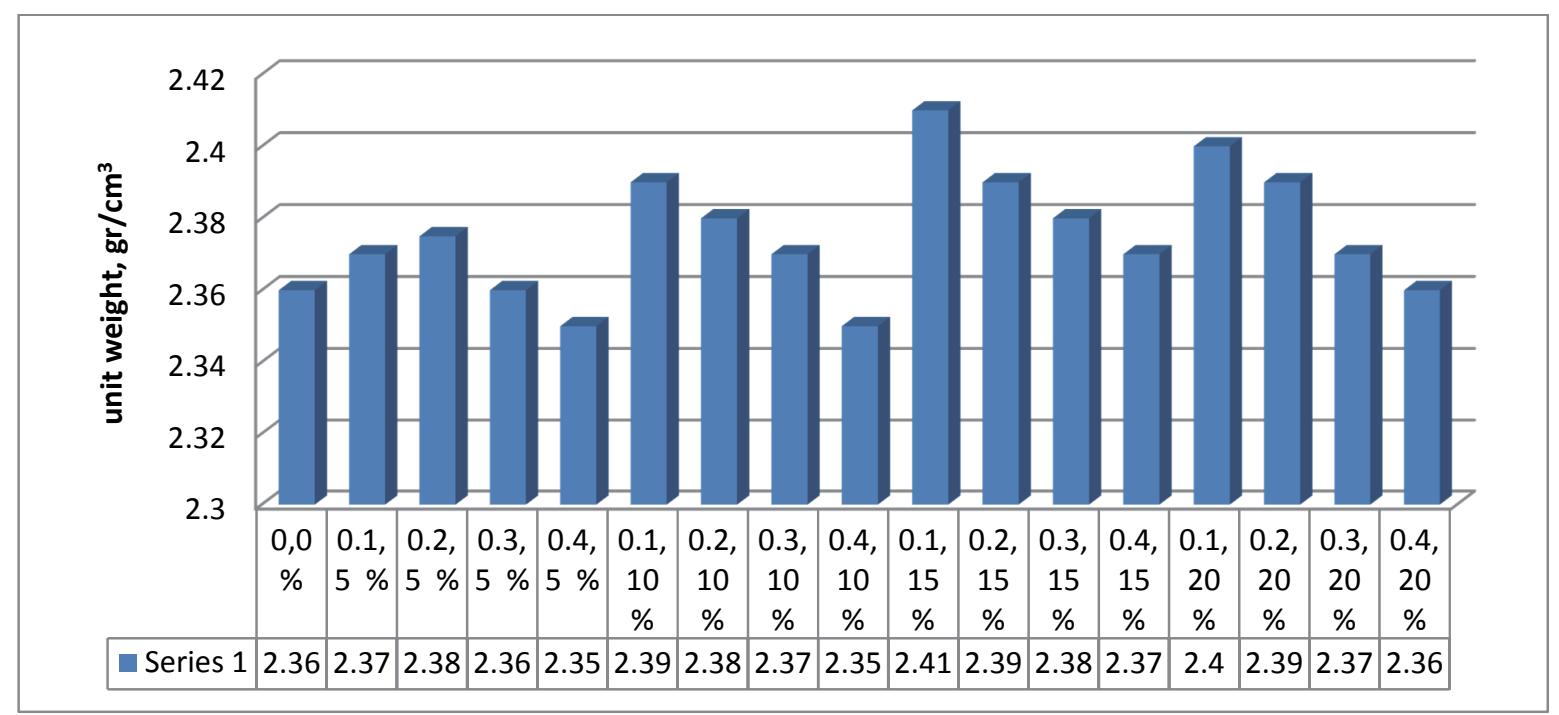

Fig. 5. The effect of adding nano-carbon black and polyester fibers on the unit weight of manufactured asphalt mixtures

\subsection{Cost analysis}

In order to investigate the economical aspect of using such modifiers in the mixture of asphalt concretes, a cost analysis also performed. As a case study the mix design proposed in Huang (2004) was used. The AASHTO method was employed for estimating the structural number SN and thickness of layers Di in a pavement. The thickness of each asphalt concrete layer can be found from:

$$
D_{i}=\frac{S N_{i}}{a_{1}}
$$


The value of SN0 was chosen as 1.97 for the asphaltic layer and the value of a1 which is related resilient module was obtained from Timm \& Priest (2006). Table 3 shows values of these two coefficients for different mixtures made of polyester and nano carbon black additives.

Table 3. Design Results

\begin{tabular}{ccccc}
\hline $\begin{array}{c}\text { Polyester fiber } \\
(\%)\end{array}$ & $\begin{array}{c}\text { Nano-carbon } \\
(\%)\end{array}$ & $\begin{array}{c}\text { Marshall stability } \\
(\mathrm{lb})\end{array}$ & $\mathrm{a}_{1}$ & $\mathrm{D}_{\mathrm{i}}$ \\
\hline 0 & 0 & 1840.841 & 0.41 & 4.804878 \\
\hline 0.1 & 5 & 2226 & 0.465 & 4.236559 \\
0.2 & 5 & 2480 & 0.47 & 4.191489 \\
0.3 & 5 & 2789 & 0.485 & 4.061856 \\
\hline 0.4 & 5 & 2833 & 0.49 & 4.020408 \\
\hline 0.1 & 10 & 2513 & 0.474 & 4.156118 \\
0.2 & 10 & 2601 & 0.48 & 4.104167 \\
\hline 0.3 & 10 & 2755 & 0.485 & 4.061856 \\
0.4 & 10 & 2866 & 0.489 & 4.02863 \\
\hline 0.1 & 15 & 2646 & 0.482 & 4.087137 \\
0.2 & 15 & 2822 & 0.49 & 4.020408 \\
\hline 0.3 & 15 & 2910 & 0.494 & 3.987854 \\
\hline 0.4 & 15 & 2932 & 0.495 & 3.979798 \\
\hline 0.1 & 20 & 2778 & 0.486 & 4.053498 \\
\hline 0.2 & 20 & 2822 & 0.488 & 4.036885 \\
\hline 0.3 & 20 & 2866 & 0.489 & 4.02863 \\
\hline 0.4 & 20 & 2976 & 0.496 & 3.971774 \\
\hline
\end{tabular}

Here costs/benefits of adding fiber and Nano materials into the mixture of asphalt concrete is investigated for a 6-line way (each direction 3 lines) for the construction length of one kilometer. It should be noted that special weight of asphalt was considered approximately $\gamma=2.3 \mathrm{ton} / \mathrm{m}^{3}$. The prices of each ton of asphalt and Nano-Carbon Black and polyester fiber (per kg) were considered about 51\$, $43 \$$ and $1 \$$, respectively.

The value of benefit due to adding two additive is obtained from Eq. (2)

Benefit $=1000 \times 6 \times 3.65 \times \frac{D_{i} \times 2.54}{100} \times \gamma \times$ asphalt price $-1000 \times 6 \times 3.65 \times \frac{D_{0} \times 2.54}{100} \times \gamma \times$ asphalt price

The value of spent cost for one-kilometer asphalt containing polyester fiber is obtained according to Eq. (3):

Cost $=1000 \times 6 \times 3.65 \times \frac{D_{i} \times 2.54}{100} \times \gamma \times 1000 \times \frac{63}{1000} \times$ additive percent $\times$ polyester fiber price

The value of spent cost for one-kilometer asphalt containing nono-carbon black is obtained according to Eq. (4):

$$
\text { Cost }=1000 \times 6 \times 3.65 \times \frac{D_{i} \times 2.54}{100} \times \gamma \times 1000 \times \frac{63}{1000} \times \text { additive percent } \times \text { black Nano carbon price }
$$

Table 4 presents the results of calculating benefit and cost. 
Table 4. The results of the cost analysis of the effect of black Nano carbon and polyester fiber to the mix

\begin{tabular}{cccccc}
\hline $\begin{array}{c}\text { Polyester fiber } \\
(\%)\end{array}$ & $\begin{array}{c}\text { Nano- } \\
\text { carbon (\%) }\end{array}$ & Benefit & Cost & Benefit-Cost & Benefit/Cost \\
\hline 0 & 0 & 0 & 0 & 0 & 0 \\
0.1 & 5 & 37082.55 & 645688 & -608606 & 0.05743 \\
0.2 & 5 & 40023.33 & 687080.9012 & -647057.5712 & 0.058251 \\
0.3 & 5 & 48481.79 & 691814.7402 & -643332.9502 & 0.070079 \\
0.4 & 5 & 51186.25 & 761910.852 & -710724.602 & 0.067181 \\
0.1 & 10 & 42331.27 & 1282805.635 & -1240474.365 & 0.032999 \\
0.2 & 10 & 45721.03 & 1293025.026 & -1247303.996 & 0.03536 \\
0.3 & 10 & 48481.79 & 1305678.524 & -1257196.734 & 0.037131 \\
0.4 & 10 & 50649.77 & 1372311.385 & -1321661.615 & 0.036908 \\
0.1 & 15 & 46832.23 & 1879198.793 & -1832366.563 & 0.024921 \\
0.2 & 15 & 51186.25 & 1874236.4 & -1823050.15 & 0.02731 \\
0.3 & 15 & 53310.37 & 1884570.617 & -1831260.247 & 0.028288 \\
0.4 & 15 & 53836.02 & 1957139.716 & -1903303.696 & 0.027507 \\
\hline 0.1 & 20 & 49027.15 & 2476332.779 & -2427305.629 & 0.019798 \\
0.2 & 20 & 50111.13 & 2492007.602 & -2441896.472 & 0.020109 \\
\hline 0.3 & 20 & 50649.77 & 2512682.818 & -2462033.048 & 0.020158 \\
0.4 & 20 & 54359.58 & 2553443.555 & -2499083.975 & 0.021289 \\
\hline
\end{tabular}

\section{Conclusion}

In this article, polyester fiber with high strength and black Nano carbon additives were used in the mixture of asphalt concrete with different percentages and the mechanical properties of the mixtures were studied experimentally using the marshal test method. The combined effect of two additives can affect significantly improve the technical characteristics, quality and durability of asphalt. However, economical aspects of using such additives should be investigated as well to employ the modified asphalt mixtures in practical field projects. The cost analysis performed in this paper, showed that asphalt mixture containing 5\% nano-carbon and $0.4 \%$ polyester fiber is a good selection both from mechanical and economical aspects. Such asphalt mixtures can be employed in regions with moderate temperatures and climate with the high level of smooth traffic.

\section{References}

Abtahi, S. M. \& Alipour, R., Hejazi, S.M., \& Sheikhzadeh, M., (2011), "studying the effect of different fibers on tensile strength property of bitumen". Journal of textile sciences and technology, 1 (1), 3134.

Abuawad, I. M., Al-Qadi, I. L., \& Trepanier, J. S. (2015). Mitigation of moisture damage in asphalt concrete: Testing techniques and additives/modifiers effectiveness. Construction and Building Materials, 84, 437-443.

Abdelfattah, H. F., Al-Shamsi, K., \& Al-Jabri, K. (2016). Evaluation of rutting potential for asphalt concrete mixes containing copper slag. International Journal of Pavement Engineering, 1-11.

Aliha, M. R. M., Bahmani, A., \& Akhondi, S. (2016). A novel test specimen for investigating the mixed mode I+ III fracture toughness of hot mix asphalt composites-Experimental and theoretical study. International Journal of Solids and Structures, 90, 167-177.

Ameri, M., Mansourian, A., Khavas, M. H., Aliha, M. R. M., \& Ayatollahi, M. R. (2011). Cracked asphalt pavement under traffic loading-A 3D finite element analysis. Engineering Fracture Mechanics, 78(8), 1817-1826.

Ameri, M., Nowbakht, S., Molayem, M., \& Aliha, M. R. M. (2016). Investigation of fatigue and fracture properties of asphalt mixtures modified with carbon nanotubes. Fatigue \& Fracture of Engineering Materials \& Structures, 39(7), 896-906.

Ameri, M., Mansourian, A., Pirmohammad, S., Aliha, M. R. M., \& Ayatollahi, M. R. (2012). Mixed mode fracture resistance of asphalt concrete mixtures. Engineering Fracture Mechanics, 93, 153167. 
Behbahani, H., Aliha, M., Reza, M., Fazaeli, H., \& Aghajani, S. (2013). Experimental fracture toughness study for some modified asphalt mixtures. In Advanced Materials Research (Vol. 723, pp. 337-344). Trans Tech Publications.

Chandak, P. G., Tapase, A. B., Sayyed, S. S., \& Attar, A. C. (2017, July). A State-of-the-Art Review of Different Conditions Influencing the Behavioral Aspects of Flexible Pavement. In International Congress and Exhibition: Sustainable Civil Infrastructures: Innovative Infrastructure Geotechnology (pp. 300-312). Springer, Cham.

Fazaeli, H., Samin, Y., Pirnoun, A., \& Dabiri, A. S. (2016). Laboratory and field evaluation of the warm fiber reinforced high performance asphalt mixtures (case study Karaj-Chaloos Road). Construction and Building Materials, 122, 273-283.

Guan, B., Xiong, R., He, R., Chen, S. F., \& Ding, D. H. (2014). Investigation of Usability of Brucite Fiber in Asphalt Mixture. International Journal of Pavement Research and Technology, 7(3), 193202.

Huang, Y. H. (2004). Pavement analysis and design.

Khalid, K. (2013). The Physical and Engineering Properties of 60/70 Bitumen with Carbon Black Additives.

Murugan, R. B., Natarajan, C., \& Chen, S. E. (2016). Material development for a sustainable precast concrete block pavement. Journal of Traffic and Transportation Engineering (English Edition), 3(5), 483-491.

Park, T., \& Lovell, C. W. (1996). Using pyrolized carbon black from waste tires in asphalt pavement. Part 1. Limestone aggregate. Final report, September 1993-May 1995 (No. PB--96-183694/XAB). Purdue Univ., Lafayette, IN (United States). Joint Highway Research Project.

Park, P., El-Tawil, S., Park, S. Y., \& Naaman, A. E. (2015). Cracking resistance of fiber reinforced asphalt concrete at $-20^{\circ} \mathrm{C}$. Construction and Building Materials, 81, 47-57.

Sabouri, M., Bennert, T., Daniel, J. S., \& Kim, Y. R. (2015). Fatigue and rutting evaluation of laboratory-produced asphalt mixtures containing reclaimed asphalt pavement. Transportation Research Record: Journal of the Transportation Research Board, (2506), 32-44.

Shafabakhsh, G. H., Mirabdolazimi, S. M., \& Sadeghnejad, M. (2014). Evaluation the effect of nano$\mathrm{TiO} 2$ on the rutting and fatigue behavior of asphalt mixtures. Construction and Building Materials, 54, 566-571.

Shukla, M., Tiwari, D., \& Sitaramanjaneyulu, K. (2014). Performance characteristics of fiber modified asphalt concrete mixes. International Journal on Pavement Engineering \& Asphalt Technology, 15(1), 38-50.

Timm, D. H., \& Priest, A. L. (2006). Material properties of the 2003 NCAT test track structural study (No. 06-01). Report.

Wang, Y., Wang, C., \& Bahia, H. (2017). Comparison of the fatigue failure behaviour for asphalt binder using both cyclic and monotonic loading modes. Construction and Building Materials, 151, 767774.

Zahedi M., \& Baharvand, B. (2017). Experimental study of Nano clay and crumb rubber influences on mechanical properties of HMA. Journal of Civil Engineering and Structures, 1(1), 10-24

Zahedi, M., \& Zarei, M. (2016). Studying the simultaneous effect of black Nanocarbon and Polyester fibers with high stability on mechanical properties of asphalt mixture. The Turkish Online Journal of Design, Art and Communication, 188-195.

Zarei, M., \& Zahedi, M. (2016). Effect of nano-carbon black on the mechanical properties of asphalt mixtures. Journal of Fundamental and Applied Sciences, 8(3S), 2996-3008.

Zhao, S., Huang, B., Shu, X., \& Ye, P. (2014). Laboratory investigation of biochar-modified asphalt mixture. Transportation Research Record: Journal of the Transportation Research Board, 2445, 56-63.

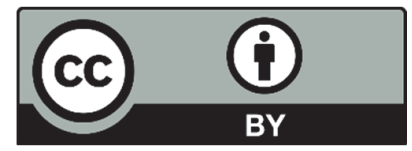

(C) 2017 by the authors; licensee Growing Science, Canada. This is an open access article distributed under the terms and conditions of the Creative Commons Attribution (CC-BY) license (http://creativecommons.org/licenses/by/4.0/). 